\title{
Diffuse Alveolar Hemorrhage Induced by Irinotecan for a Patient with Metastatic Thymic Carcinoma: A Case Report and Literature Review
}

\author{
Sung-Ho Kim ${ }^{1,2}$, Seigo Minami ${ }^{2}$, Yoshitaka Ogata ${ }^{2}$, Suguru Yamamoto ${ }^{1,2}$ and Kiyoshi Komuta ${ }^{2}$
}

\begin{abstract}
We herein report a 73-year-old Japanese woman with metastatic thymic carcinoma who developed diffuse alveolar hemorrhage (DAH) during irinotecan chemotherapy. She presented with a mild fever and exertional dyspnea after the second cycle of weekly irinotecan monotherapy. Chest images showed diffuse ground-glass opacities. The diagnosis of DAH was based on the findings of the bronchoalveolar lavage fluid, which was bloody and contained hemosiderin-laden macrophages. The discontinuation of irinotecan and introduction of oral prednisolone improved her symptoms and chest abnormal shadows. This is the first case of DAH caused by irinotecan.
\end{abstract}

Key words: diffuse alveolar hemorrhage, drug-induced, irinotecan, thymic carcinoma, bronchoalveolar lavage, steroid

(Intern Med 56: 1697-1700, 2017)

(DOI: 10.2169/internalmedicine.56.8349)

\section{Introduction}

Diffuse alveolar hemorrhage (DAH) is a serious and lifethreatening event. A variety of diseases, conditions and drugs can cause DAH. Although anti-coagulants and antiplatelet agents are the most frequent candidates, anti-tumor drugs can also induce this event.

Irinotecan is a cytotoxic drug classified as plant alkaloid and topoisomerase I inhibitor and has been approved for use against a variety of cancers. Interstitial pneumonia is a wellknown and characteristic adverse effect of this anti-tumor drug. However, to our knowledge, there have been no reports of DAH caused by irinotecan.

We herein report a rare case of DAH caused by irinotecan in patients with metastatic thymic carcinoma.

\section{Case Report}

A 73-year-old Japanese woman complained of a fever $\geq 38^{\circ} \mathrm{C}$ and exertional dyspnea at her regular clinic visit in the middle of July 2014. In May 2014, she had started fifth- line systemic chemotherapy of weekly irinotecan monotherapy $\left(60 \mathrm{mg} / \mathrm{m}^{2}\right.$, Days 1,8 and 15 , every 4 weeks) for her metastatic thymic carcinoma (squamous cell carcinoma type). These symptoms appeared on the 23rd day of the second cycle in the middle of July 2014. We found these symptoms on the 29th day of the second cycle. Chest X-ray suggested light ground-glass shadow, especially in the right upper lung field. Computed tomography (CT) showed diffuse ground-glass shadow spreading in all of the lung fields, in addition to shrinkage of the lung metastases (Fig. 1). The differential diagnoses based on her clinical course and these chest image findings included congestive heart failure, druginduced pneumonia and pneumocystis pneumonia. We discontinued the chemotherapy and recommended her immediate hospitalization. However, she declined immediate admission at that time. During the four days she waited until ultimately allowing admission, her symptoms, respiratory conditions and abnormal shadow on chest X-ray did not change remarkably.

Since April 2007, she had undergone thymectomy, left upper lung partial resection, left lower lobe resection, stereotactic radiation therapy to the right lung metastases and sys-

${ }^{1}$ Department of ER Medical Center, Osaka Police Hospital, Japan and ${ }^{2}$ Department of Respiratory Medicine, Osaka Police Hospital, Japan Received for publication October 2, 2016; Accepted for publication October 20, 2016

Correspondence to Dr. Seigo Minami, seigominami@oph.gr.jp 

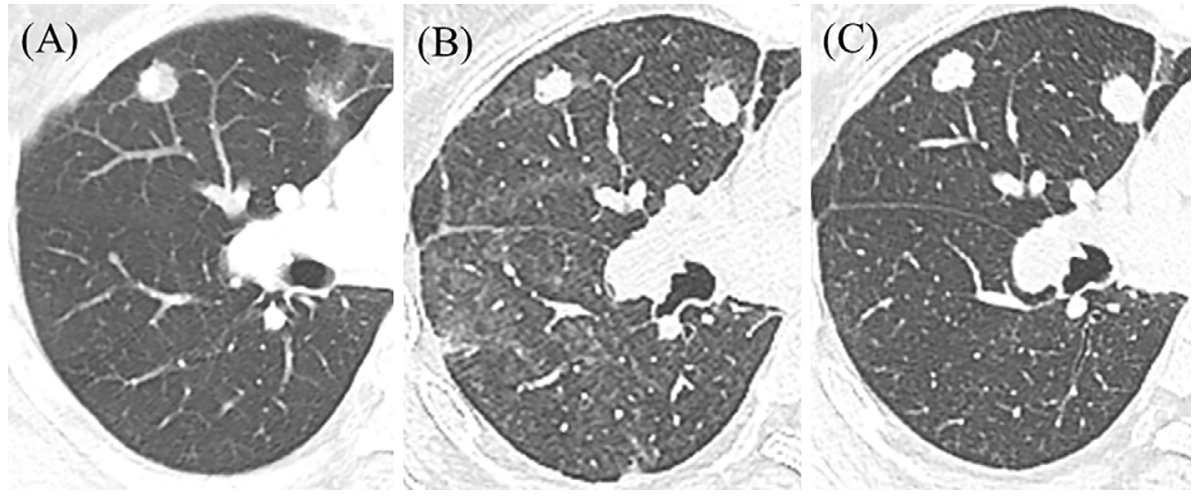

Figure 1. (A) Chest CT before irinotecan in May 2014, (B) chest high-resolution CT (HRCT) at the end of the second cycle of irinotecan in late July 2014, when the respiratory symptoms and groundglass shadow appeared, and (C) HRCT in late August 2014, one month after introduction of steroid therapy.

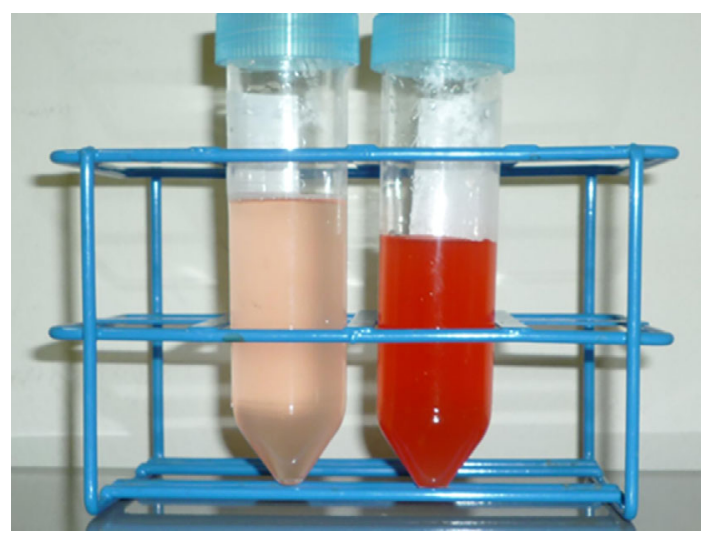

Figure 2. The broncho-alveolar lavage fluid gradually became bloody from the left tube to the right tube.

temic chemotherapies, including the administration of carboplatin plus paclitaxel twice, cisplatin plus etoposide and gemcitabine. Except for febrile neutropenia, she did not experience severe toxicities during her previous treatment. Her medical, family and social histories were unremarkable. Her current medication included loxoprofen sodium, rebamipide and pregabalin. These medications had been administered for years. Except for anti-tumor drugs, she had not started any new regular drugs for more than three years. She was not using any anticoagulants or antiplatelet agents.

Her vital signs on admission were as follows: heart rate 68 beats/min with a regular rhythm, $\mathrm{SpO}_{2} 95 \%$ (on room air) and blood pressure 124/60 $\mathrm{mmHg}$. A physical examination revealed neither murmur in her heart sound nor rale in her breath sounds. Her blood cell counts were as follows: hemoglobin $9.6 \mathrm{~g} / \mathrm{dL}$, hematocrit $28.6 \%$, white blood cells $6,300 / \mathrm{mm}^{3}$ (neutrophils $50.7 \%$, lymphocyte $30.6 \%$, eosinophils $2.2 \%$ ), platelets $288,000 / \mathrm{mm}^{3}$. Her C-reactive protein and lactate dehydrogenase were slightly elevated to $1.91 \mathrm{mg} /$ $\mathrm{dL}$ and $311 \mathrm{U} / \mathrm{L}$, respectively. Pneumocystis pneumonia and anti-neutrophil cytoplasmic antibody (ANCA)-associated vasculitis were unlikely because $\beta$-D-glucan, proteinase- 3 and myeloperoxidase ANCA were undetectable. Congestive

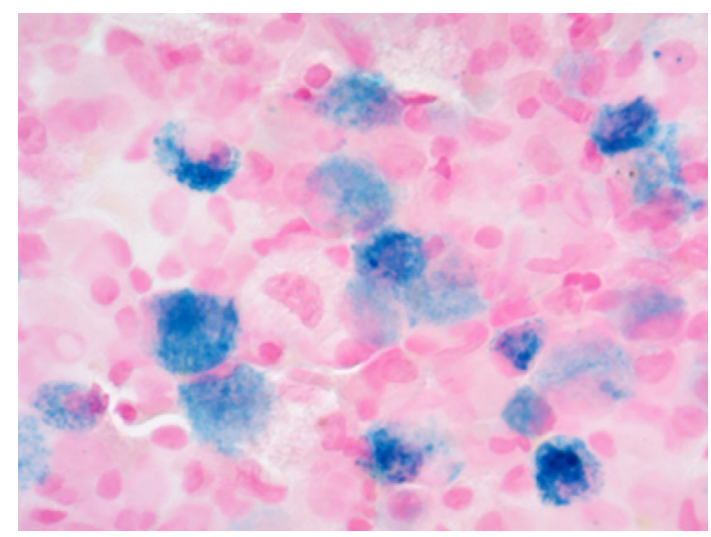

Figure 3. Hemosiderin-laden macrophages with positive staining of iron (Berlin blue) in the bronchoalveolar lavage fluid.

heart failure was also doubtful because her brain natriuretic peptide levels were slightly elevated to $46.7 \mathrm{pg} / \mathrm{mL}(<18.4$ $\mathrm{pg} / \mathrm{mL}$ ). Coagulation was also within the normal range. Her uridine diphosphate glucoronosyltransferase (UGT1A1)*28 and $* 6$ gene polymorphisms were wild-type.

We performed bronchoscopy on the 33rd day of the second course, in late July 2014. This examination did not find any apparent bleeding in the airway, trachea and bronchus. Bronchoalveolar lavage fluid (BALF) recovered from $\mathrm{B}_{4}$ in the right middle lobe, with a recovery rate of $40 \%(60 \mathrm{~mL} /$ $150 \mathrm{~mL}$ of saline), gradually became bloody (Fig. 2). The routine microbiology culture of BALF did not detect bacterial or fungal infection. The cell count analysis (total cell count $5.1 \times 10^{5}$ cells $/ \mathrm{mL}$ ) of BALF indicated the following: alveolar macrophages 58\%, neutrophils 3\%, lymphocytes $38 \%$ and eosinophils $1 \%$. BALF contained macrophages with positive staining of iron (Berlin blue) but no atypical cells suspected of malignancy (Fig. 3). We also performed a transbronchial lung biopsy (TBLB) from the right $\mathrm{B}_{2}, \mathrm{~B}_{8}$ and $B_{9}$. Although a small number of lymphocytes were scattered in the alveolar interstitium and immunochemical staining for Pneumonositis jirovecii was negative, we could not detect 
Table. Review of Diffuse Alveolar Hemorrhage Caused by Anti-tumor Drugs in Patients with Solid Tumor in the English or Japanese Literatures.

\begin{tabular}{|c|c|c|c|c|c|c|c|}
\hline References & Drugs & $\begin{array}{l}\text { Cancer } \\
\text { (Histology) }\end{array}$ & $\begin{array}{l}\text { Patients } \\
\text { (Age, sex) }\end{array}$ & $\begin{array}{l}\text { Onset } \\
\text { timing }\end{array}$ & Diagnosis & $\begin{array}{l}\text { Initial } \\
\text { treatment }\end{array}$ & $\begin{array}{l}\text { Outcomes of } \\
\text { DAH }\end{array}$ \\
\hline 1 & Gemcitabine & $\begin{array}{l}\text { Lung } \\
\text { (Large) }\end{array}$ & 72 male & 2 weeks & BAL & $\begin{array}{l}\text { Steroid pulse (mPSL } 240 \mathrm{mg} \text { for } 3 \\
\text { days), Intubation and mechanical } \\
\text { ventilator support }\end{array}$ & Improved \\
\hline 2 & Gefitinib & Lung (Ad) & 56 male & 4 weeks & BAL & $\begin{array}{l}\text { Steroid pulse (high dose mPSL), } \\
\text { full-face mask ventilation }\end{array}$ & $\begin{array}{l}\text { Improved and } \\
\text { discharged }\end{array}$ \\
\hline 6 & Gemcitabine & Lung (Ad) & 51 male & 2 months & $\begin{array}{l}\text { BF } \\
\text { Autopsy }\end{array}$ & $\begin{array}{l}\text { Steroid pulse (mPSL 500mg for } 3 \\
\text { days), Intubation and mechanical } \\
\text { ventilator support }\end{array}$ & Dead \\
\hline 10 & Sunitinib & $\begin{array}{l}\text { Renal cell } \\
\text { carcinoma }\end{array}$ & 67 male & 5 days & $\begin{array}{l}\text { BAL, } \\
\text { Autopsy }\end{array}$ & $\begin{array}{l}\text { Carbazochrome sodium sulfonate } \\
\text { hydrate }\end{array}$ & Improved \\
\hline 8 & Gefitinib & Lung (Ad) & 74 female & 2 weeks & BAL & Only withdrawal of gefitinib & Improved \\
\hline 9 & Gemcitabine & Pancreatic & 69 female & 212 days & $\mathrm{BF}$ & Steroid pulse (mPSL $1 \mathrm{~g}$ for 3 days) & $\begin{array}{l}\text { Recovered and } \\
\text { discharged }\end{array}$ \\
\hline 4 & Everolimus & Brest & 65 female & 4 months & BAL & Steroid mini-pulse & $\begin{array}{l}\text { Recovered and } \\
\text { discharged }\end{array}$ \\
\hline 7 & Crizotinib & Lung (Ad) & 63 male & 7 days & $\mathrm{BF}$ & $\begin{array}{l}\text { Steroid pulse }(1 \mathrm{~g} / \text { day }) \text {, sivelestat, } \\
\text { Intubation and mechanical ventilator } \\
\text { support }\end{array}$ & Dead \\
\hline 3 & Bevacizumab & Lung (Ad) & 71 female & 32 days & Autopsy & None & Dead \\
\hline 12 & $\begin{array}{l}\text { Erlotinib+ } \\
\text { Paclitaxel+ } \\
\text { RT }\end{array}$ & Esophageal & 40 male & 1 month & BAL & $\begin{array}{l}\text { Steroid pulse (mPSL } 1 \mathrm{~g} \text { ) and } \\
\text { non-invasive ventilator support }\end{array}$ & $\begin{array}{l}\text { Recovered and } \\
\text { discharged }\end{array}$ \\
\hline 5 & Pemetrexed & Lung (Ad) & 67 male & 4 months & BAL & Steroid pulse (mPSL $1 \mathrm{~g}$ for 3 days) & Dead \\
\hline Our case & Irinotecan & $\begin{array}{l}\text { Thymic } \\
\text { (SQ) }\end{array}$ & 73 female & 7-8 weeks & BAL & Oral PSL (0.5mg/kg/day) & $\begin{array}{l}\text { Recovered and } \\
\text { discharged }\end{array}$ \\
\hline
\end{tabular}

Ad: adenocarcinoma, BAL: bronchoalveolar lavage, BF: bronchospcopy, DAH: diffuse alveolar hemorrhage, Large: large cell undifferentiated carcinoma, mPSL: methylprednisolone, PSL: prednisolone, SQ: squamous cell carcinoma, TBLB: transbronchial lung biopsy

hemosiderin-laden macrophages in the TBLB specimens. Based on these bronchoscopic findings, we diagnosed the patient with drug-induced DAH and discontinued irinotecan and started oral prednisolone $(0.5 \mathrm{mg} / \mathrm{kg} / \mathrm{day})$. Prednisolone was gradually tapered and discontinued two months later. CT in late August 2014 showed disappearance of the ground-glass shadows (Fig. 1).

We did not try a challenge re-administration of irinotecan. Thereafter, she received docetaxel in September 2014 and S1 in November 2015 but did not suffer from alveolar hemorrhage from these drugs. She died due to a worsening of thymic carcinoma in March 2016 at another hospital.

\section{Discussion}

Regarding pulmonary toxicity caused by anti-tumor drugs, DAH was much rarer than interstitial pneumonia. We found only 12 previous cases of DAH caused by anti-tumor drugs (Table) (1-12). Tyrosine kinase inhibitors were the most frequent causative drugs $(2,7,8,10,11)$, while cytotoxic drugs were responsible in four cases, gemcitabine in three $(1,6,9)$ and pemetrexed in one (5). This was the first case of irinotecan-induced DAH.

Our review of previous cases showed that DAH induced by anti-tumor drugs has a varied clinical course. Patients' backgrounds were diverse in sex, age and cancer type. The timing of the onset from the start of the causative drug ranged from a sudden onset with an interval of several days or a few weeks to a late onset requiring more than one month. This onset timing did not correlate with the disease outcomes. Some patients with a sudden onset successfully recovered $(1,8,10)$, while others with a late onset unfortunately experienced worsening respiratory failure and death $(5,6)$. Depending on the severity of the events, the treatments ranged from only discontinuing the candidate drug (8) to high-dose steroid pulse therapy under intubated mechanical ventilator support in intensive care units $(1,6,7)$. Except for a postmortem autopsy case (3), bronchoscopy was essential for a prompt and definite diagnosis of DAH. Thus, when encountering a patient with respiratory symptoms and diffuse ground-glass shadow during chemotherapy, we should not hesitate to perform bronchoscopy.

Compared with previous cases, our case was characteristic with a late onset of 7 to 8 weeks' interval and mild severity requiring only oral prednisolone. The plausible pathogeneses of DAH include direct pharmacological effects to alveolar micro-capillaries and indirect effects via the stimulation of inflammatory reactions or an immunological mechanism (13). Although the pathogenesis in our case was un- 
known, the latter hypothetical pathogenesis seems unlikely because we easily tapered off steroid therapy and did not experience recurrence of DAH. A few patients have suffered from recurred and deteriorated DAH during tapering of steroid therapy (5-7), suggesting some underlying immunological reactions.

The interpretation of our case has some limitations. First, we did not comprehensively investigate the possibility of connective tissue diseases. However, DAH due to connective tissue disease was unlikely in our case because she had not shown any characteristic physical findings. Second, we did not check for valvular disorders by ultrasound cardiography. Mitral valve regurgitation has been reported to be responsible for DAH $(14,15)$. Because we did not detect murmur, we do not think that valvular diseases were associated in our case. Third, we were unable to clearly differentiate druginduced DAH from drug-induced pneumonia. Her history of medications excluded pulmonary damage induced by any drugs other than irinotecan. In these two diseases, both the alveolar and interstitial areas are commonly damaged. As a result, both the clinical and pathological findings are similar between the diseases. However, our bronchoscopic findings suggested that DAH was the main condition in our case.

In conclusion, we describe the first case of irinotecaninduced DAH. The possibility of DAH should be noted as a result of irinotecan treatment.

The authors state that they have no Conflict of Interest (COI).

\section{References}

1. Carron PL, Cousin L, Caps T, et al. Gemcitabine-associated diffuse alveolar hemorrhage. Intensive Care Med 27: 1554, 2001.

2. Ieki R, Saitoh E, Shibuya M. Acute lung injury as a possible adverse drug reaction related to gefitinib. Eur Respir J 22: 179-181, 2003.

3. Ikeda S, Sekine A, Kato T, et al. Diffuse alveolar hemorrhage as a fatal adverse effect of bevacizumab: an autopsy case. Jpn J Clin Oncol 44: 497-500, 2014.

4. Junpaparp P, Sharma B, Samiappan A, Rhee JH, Young KR. Everolimus-induced severe pulmonary toxicity with diffuse alveo- lar hemorrhage. Ann Am Thorac Soc 10: 727-729, 2013.

5. Kurimoto R, Sekine I, Iwasawa S, et al. Alveolar hemorrhage associated with pemetrexed administration. Intern Med 54: 833-836, 2015.

6. Nagashima O, Tajima K, Ito J, et al. A case of non-small cell lung cancer accompanied with hemorrhage after chemotherapy including gemcitabine. Nihon Kokyuki Gakkai Zasshi 44: 215-219, 2006 (in Japanese, Abstract in English).

7. Ono A, Takahashi T, Oishi T, et al. Acute lung injury with alveolar hemorrhage as adverse drug reaction related to crizotinib. J Clin Oncol 31: e417-e419, 2013.

8. Sakoda Y, Kitasato Y, Kawano Y, Mizuta Y, Takata S, Kawasaki M. A case of alveolar hemorrhage caused by gefitinib. Nihon Kokyuki Gakkai Zasshi 49: 506-510, 2011 (in Japanese, Abstract in English).

9. Tanaka M, Matsumoto I, Shinzeki M, et al. A case of interstitial lung disease associated with gemcitabine treatment in a patient with locally advanced pancreatic cancer following proton beam radiotherapy. Gan To Kagaku Ryoho 39: 2158-2160, 2012 (in Japanese, Abstract in English).

10. Yamada T, Ohtsubo K, Izumi K, et al. Metastatic renal cell carcinoma complicated with diffuse alveolar hemorrhage: a rare adverse effect of sunitinib. Int J Clin Oncol 15: 638-641, 2010.

11. Yano S, Nakataki E, Ohtsuka S, et al. Retreatment of lung adenocarcinoma patients with gefitinib who had experienced favorable results from their initial treatment with this selective epidermal growth factor receptor inhibitor: a report of three cases. Oncol Res 15: 107-111, 2005.

12. Zhao CH, Liu RR, Lin L, et al. Diffuse alveolar hemorrhage after erlotinib combined with concurrent chemoradiotherapy in a patient with esophageal carcinoma. Int J Clin Exp Med 7: 4492-4497, 2014.

13. Higenbottam T, Kuwano K, Nemery B, Fujita Y. Understanding the mechanisms of drug-associated interstitial lung disease. $\mathrm{Br} \mathrm{J}$ Cancer 91 (Suppl 2): S31-S37, 2004.

14. Marak CP, Joy PS, Gupta P, Bukovskaya Y, Guddati AK. Diffuse alveolar hemorrhage due to acute mitral valve regurgitation. Case Rep Pulmonol 2013: 179587, 2013.

15. Spence TH, Connors JC. Diffuse alveolar hemorrhage syndrome due to 'silent' mitral valve regurgitation. South Med J 93: 65-67, 2000 .

The Internal Medicine is an Open Access article distributed under the Creative Commons Attribution-NonCommercial-NoDerivatives 4.0 International License. To view the details of this license, please visit (https://creativecommons.org/licenses/ by-nc-nd/4.0/).

(C) 2017 The Japanese Society of Internal Medicine http://www.naika.or.jp/imonline/index.html 